Research Article

\title{
The Evolutionary Game of Trust in Public-Private Partnership Project Networks
}

\author{
Xiangtian Nie, ${ }^{1}$ Kai Feng, ${ }^{1}$ Guoxiang Zhao, ${ }^{2}$ Tianyu Fan, ${ }^{1}$ and Shengnan Wang $\mathbb{D}^{2}$ \\ ${ }^{1}$ North China University of Water Resources and Electric Power, Zhengzhou, China \\ ${ }^{2}$ Institute of Psychology and Behaviour, Henan University, Kaifeng, China \\ Correspondence should be addressed to Shengnan Wang; nicolesnwang@vip.henu.edu.cn
}

Received 21 January 2021; Revised 14 June 2021; Accepted 1 July 2021; Published 19 July 2021

Academic Editor: Georgios Dounias

Copyright ( $\odot 2021$ Xiangtian Nie et al. This is an open access article distributed under the Creative Commons Attribution License, which permits unrestricted use, distribution, and reproduction in any medium, provided the original work is properly cited.

In public-private partnership (PPP) projects, the government plays a role as both regulator and participant. Trust between the government and the private sector is important as it may affect project performance and even cause the problem of a breach of contract, which may lead to project failure. Little is known, however, about the formation and evolution mechanisms of trust in this context. This study analyses the complex evolution of trust in PPP project networks. An evolutionary game of trust model between government and the private sector is established and analysed, the strategic equilibrium points are obtained by solving the replication dynamic equation, and the Jacobian matrix and differential equation stability theory are introduced to analyse the stability of the equilibrium points. The results reveal the relationships among the stable state of trust, the initial state of trust, and the payment matrix, indicating that the payment matrix can effectively shape the evolution process and stable state of trust to influence performance. This study provides a novel contribution in solving the complex trust problem in PPP project networks and it provides a new analytical tool for PPP project management practice.

\section{Introduction}

In recent years, project networks have attracted the attention of many researchers in the field of project management. Scholars have explored the relationship between stakeholders of projects and their influencing factors and the evolutionary mechanism by using theories and methods, such as game theory, social network analysis, and empirical research, and achieved rich results [1-4]. However, as a relatively new field of research, these networks still need continuous and in-depth investigation, to extend the research parameters and to promote a better understanding of their development. With the global popularity of the public-private partnership (PPP) mode, it is of great significance to study project networks in the context of PPP models. Government and the private sector are important nodes of the network in PPP projects. This study focuses on the evolutionary mechanism of trust between the government and the private sector in PPP projects.

PPP projects refer to public infrastructure and public service projects jointly participated in by the government and private sector [5]. The PPP project mode is widely used in transportation, water conservancy, environmental protection, public health, and other fields worldwide [6]. Compared to traditional models where the government alone provides public goods and services, the advantages of the PPP mode are mainly reflected in enhanced economic and time efficiencies, increased investment in infrastructure projects, the improved financial soundness of the public and private sectors, improved quality of infrastructure/public services, long-term planning, an enhanced reputation, and more steady development of the private sector, among others. The purpose of PPP projects is to achieve a win-win situation between the government and private sector; therefore, scholars put forward different guarantee mechanisms to ensure the benefits of the two participants. For instance, Carbonara and Pellegrino developed a methodology to calculate the optimal maximum and minimum values of the revenue for achieving fairly risk-sharing and win-win condition between the government and private sector [7]. Moreover, Lomoro et al. proposed a risk-sharing 
optimizing method for PPP projects by project financing contracts; its purpose is also to improve project performance and achieve a win-win situation between the government and private sector [8].

PPP projects tend to have long investment cycles and a greater scale. Due to the incomplete nature of contracts and the bounded rationality of decision-making, a longer contract period results in greater uncertainty in the transaction process and a lesser likelihood that a formal contract will be implemented, resulting in higher transaction costs [9]. Research shows that interorganisational trust can effectively reduce transaction costs. According to Mayer et al., the connotation of trust is that one party believes and depends on the other and is willing to accept the harm that may be caused by future uncertainty [10]. Laan et al. insisted that, in a project, trust is defined as the expectation that the trustor believes that the trustee will not disappoint them even if there is a possibility of opportunistic behaviour [11]. Du focused on examining trust between organisations under the PPP model from an economic perspective; trust is a form of expectation, where the trustor bears the risk of the loss of benefits caused by uncertainty while assuming that the trustee will not act opportunistically [5]. Connelly et al. believed that integrity-based trust can reduce the need for complex contracts and thus reduce ex-ante transaction costs, whereas competence-based trust can realise complex contracts and thus avoid excessive costs associated with ex-ante transactions [12]. Adler argued that trust reduces agency risk [13] and Ryall and Sampson indicated that trust can reduce the need for costly monitoring [14]. Integrity-based trust entails less fear of opportunism [15], while competencybased trust expresses confidence in a partner's ability to accomplish a specific task [16]. Integrity-based trust promotes information sharing [17], strengthens cooperation [18], and reduces the need for formal contracts $[19,20]$.

However, although scholars have done substantial research on the influencing factors and functions of interorganisational trust in a project context and formed a relatively stable understanding, there is limited research on the formation and the evolution processes and its mechanism. Therefore, the objective of this study is to analyse the trust game between the government and private sector in PPP project networks by constructing an evolutionary game model, from a dynamic perspective, to explain these change processes and the final stable state of trust strategies of both parties.

The expectations of trust may affect the level of contribution or input from both parties. A high level of trust can effectively compensate for the natural imperfection of formal contracts, reducing their rigidity and transaction costs, limiting opportunistic behaviours, and improving cooperation efficiency, thereby enhancing project performance.

\section{Literature Review}

Most research on interorganisational trust employs empirical approaches to the associated causes and consequences. These factors include reputation, communication and information sharing, interdependence, cooperative experiences, equity, geographical distance, special asset investment, sense of value, capabilities, and culture, among others [21]. Brinkhoff et al. found that trust can significantly affect the success of project management by influencing the commitment of executives and employees [22]. Interorganisational trust can, among other outcomes, enhance the satisfaction of partners through their technical contribution, goal achievement, timeliness, and innovation. This satisfaction enhances the willingness of both parties to establish lasting, cooperative, and committed relationships, resulting in the improvement of organisational performance [23]. Lui et al. indicated that enterprise familiarity, partner reputation, and specific assets affect interfirm cooperation through trust [24]. Zhang et al. investigated 295 subcontractor relationships in China's construction industry and noted that perceived safeguards play a mediating role between contract complexity and interorganisational trust, while special-purpose investments moderate the positive effect of contract complexity on perceived safeguards [25]. Trust will enable partners to improve their governance approach to informal relationships, promote mutual plan sharing, and foster flexibility when delivering performance improvements [26, 27]. Indiscriminate trust, however, may lead to blind faith. Excessive reliance on the information, abilities, and resources provided by a partner also reduced the capability of the trustor to monitor opportunistic behaviours resulting in excessive embedding which increased the risk of losses suffered by the enterprise [28, 29]. Many studies assume that interorganisational trust is symmetric; however, Graebner et al. argued that there was no clear evidence that interorganisational trust is symmetric and indicated that trust between organisations may be more complex in cases of asymmetry [30]. Li et al. noted six key factors affecting the asymmetric trust behaviours in projects. Power imbalances, information asymmetry, and cognitive differences had negative effects on the mutually trusting behaviours within organisations, while performance, ability, and relationship satisfaction had positive effects [31].

Trust is a recursive state caused by behaviours or choices and is thus not a static phenomenon but rather a dynamic process of evolution. Studying this process is key to understanding the relationship between the two parties in a transaction $[32,33]$. Laan believed that the dynamic nature of trust originated out of risk. Therefore, the key to trust is to find the balance between trust and control as two vital components of project risk management [34]. According to $\mathrm{Fu}$ and $\mathrm{Gu}$, when the trust level and degree of dependence are proportionate, the optimum trust among enterprises within a cluster will be achieved and will evolve dynamically throughout the different growth stages of the partnership [35]. Some scholars have studied the formation mechanism of interorganisational trust from the perspective of game theory. Xiao and Gu illustrated how interorganisational trust was formed by analysing the two-stage game between two enterprises in a homogeneous product market through the Cournot model [36]. Yuan and Zhang designed a trust relationship construction path with a trigger strategy targeting the problem that all parties involved in trust often fall into the prisoner's dilemma [37]. 
Classic game theory assumes that agents are rational and share common knowledge; that is, "all players are rational; all players know that all players are rational; all players know that all players know that all players are rational." However, the rationality that people show in most complex decision problems cannot fully satisfy the requirement of complete rationality in classical game theory. In the analysis of the trust game between the government and the private sector in PPP projects, these actors are unable to avoid their limitations in rationality. If we reject this and insist on a game analysis under the sole assumption of complete rationality without a realistic basis (and do not discuss the influence of rationality limitations on the game), the process and outcomes will fail the expected rigour of scientific analysis, explanation, and prediction for real-life problems. Evolutionary game theory assumes bounded rationality, in which players learn from each other while competing, thereby adapting to each other in the game. Furthermore, players with bounded rationality have limited decision-making ability, hence they cannot correctly calculate their income and make the best decision simultaneously or instantaneously. Instead, they form a stable state of equilibrium through constant trial-and-error and imitation to learn strategies with higher income. In recent years, evolutionary game theory has attracted extensive attention. Zhu et al. established an evolutionary game model for the sustainability of information security investment in social networks and highlighted that the optimal strategy is related to the profit growth coefficient and investment cost and is significantly affected by free-rider returns [38]. Based on evolutionary game theory, Luo analysed the cooperative default penalty mechanism among enterprises [39]. Li et al. further studied ecological compensation in the Taihu Basin of China [40]. Evolutionary game theory also provides a practicable research tool for the study of patterns of cooperation among manufacturers and suppliers in supply chain management $[41,42]$. For PPP projects, during their long life-cycle, the government and private sector cooperate around a unified project goal. There are, however, natural differences in their motivations whereby the public service, legality, and coerciveness of the government are pitted against the profit-driven and opportunist tendencies of the private sector, resulting in different trust states that lead to varied returns. Thus, both parties will constantly adjust their trust strategies according to these returns and finally establish a balanced and stable state. This study, therefore, constructs an asymmetric evolutionary game model to study the trust game and its evolution path between the government and private sector in PPP projects.

\section{Methods}

Since interorganisational trust has come into the field of research, many scholars have discussed its evolution. Abdullah and Khadaroo indicated that trust and control in the PPP project are not static phenomena but evolve through interaction and learning about each other [43]. Through case studies, English and Baxter confirm that trust between the government and private sector in PPP projects is constantly evolving [44]. Furthermore, Dewulf and Garvin proposed that interorganisational trust in PPP projects is influenced by changing project conditions as well as established contractual frameworks, shifting responsibilities, evolving relationships, and external pressures [45]. In order to study the evolution of trust in the PPP project, some researchers analysed the evolution of trust based on the classic game theory. For instance, Huang and Wilkinson proposed a process model of the dynamics and evolution of trust in business relations based on a view of business relations as complex adaptive systems. They believe that trust changes depending on the experience and outcomes of the actions and interactions and other events taking place over time in the focal as well as in connected relations [46]. Kumar et al. operationalize trust and trustworthiness using the trust game with the trustor's investment and the trustee's return of the investment as the two key parameters [47]. However, in project practice, organisations cannot meet the requirements of perfect rationality of classical game theory in most complex decision problems. Evolutionary game theory provides an analysis framework which is closer to project practice, it assumes that the players are bounded rational, and the players constantly adjust their strategies through learning in the game process until the whole system reaches a stable state. Therefore, this paper introduces an evolutionary game to analyse the trust evolution between government and private sector in PPP projects.

3.1. Model Description. In practice, the government and private sector share the same project objectives but pursue their own specific benefits. Ideally, they fully trust each other with both parties keeping their promises and avoiding speculation. This assumes that the government induces the private sector to participate in public goods production to improve economic efficiency, increases infrastructure project investments, improves the quality of infrastructure and public services, and reduces financial pressures. The private sector, meanwhile, secures profits and improves brand value resulting in a win-win situation. In practice, however, the private sector's losses in PPP projects are often caused by changes in laws, impaired government credibility, and fluctuations in market demand. The failure of private sector financing leads to unfinished projects; conversely, sustained and excessive profits emerge through controlling the price of public goods. These problems have led to mistrust between the parties.

3.2. Game Model Construction. In the game of trust between the government and private sector, there is the same strategy space, $S=\{$ trust, distrust $\}$. If the willingness of the government to choose the trust strategy is $p$, then their willingness to choose the distrust strategy is $1-p$. Likewise, if the willingness of the private sector to choose the trust strategy is $q$, then their willingness to choose the distrust strategy is $1-q, p \in[0,1], q \in[0,1]$. Assuming that the benefits to both players in the game can be quantified, the payoff matrix in Table 1 can be used to represent these benefits under different strategy profiles. 
TABLe 1: Payoff matrix of the evolutionary game between the government and private sector.

\begin{tabular}{lccc}
\hline & \multicolumn{2}{c}{ Private sector } \\
& & Trust $\left(S_{21}\right)$ & Distrust $\left(S_{22}\right)$ \\
\hline \multirow{2}{*}{ Government } & Trust $\left(S_{11}\right)$ & $C_{1}, C_{2}$ & $D_{1}, D_{2}$ \\
& Distrust $\left(S_{12}\right)$ & $V_{1}, V_{2}$ & $W_{1}, W_{2}$ \\
\hline
\end{tabular}

$C_{1}$ and $C_{2}$ in Table 1 represent the payoff of the government and private sector, respectively, when both the government and private sector choose the trust strategy. $D_{1}$ and $D_{2}$ represent the payoff of the government and private sector, respectively, when the government chooses the trust strategy and the private sector chooses the distrust strategy. $V_{1}$ and $V_{2}$ represent the payoff of the government and private sector, respectively, when the government chooses the distrust strategy and private sector chooses the trust strategy. $W_{1}$ and $W_{2}$ represent the payoff of the government and private sector, respectively, when both government and private sector choose the distrust strategy.

According to the payoff matrix, the expected payoff of the government's trust strategy $E\left(S_{11}\right)$ is

$$
E\left(S_{11}\right)=q C_{1}+(1-q) D_{1} .
$$

The expected payoff of the government's distrust strategy $E\left(S_{12}\right)$ is

$$
E\left(S_{12}\right)=q V_{1}+(1-q) W_{1} .
$$

The average expected payoff of the government $E(G)$ is

$$
E(G)=p \mathrm{E}\left(S_{11}\right)+(1-p) \mathrm{E}\left(S_{12}\right) .
$$

The expected payoff of the private sector's trust strategy $E\left(S_{21}\right)$ is

$$
E\left(S_{21}\right)=p C_{2}+(1-p) V_{2} .
$$

The expected payoff of the private sector's distrust strategy $E\left(S_{22}\right)$ is

$$
E\left(S_{22}\right)=p D_{2}+(1-p) W_{2} .
$$

The average expected payoff of the private sector $E(P)$ is

$$
E(P)=q E\left(S_{21}\right)+(1-q) E\left(S_{22}\right) .
$$

Construct an evolutionary game replicate dynamic equation following Friedman's approach [48]. The dynamic change of the probability of a player's strategy type is the core of evolutionary game analysis, and the key is the speed of dynamic change (the direction can be reflected by the sign of the speed). In general, the dynamic change of the probability of strategy type of player depends on two factors, one is the probability of the strategy type, the other is the extent of the benefit of the strategy exceeds the average benefit. Therefore, the functions $F(p)$ and $G(q)$ are conducted to represent the change rate of the willingness of choosing trust strategy by government and private sector over time, respectively:

$$
\left\{\begin{array}{l}
F(p)=\frac{\mathrm{d} p}{\mathrm{~d} t}=p\left[E\left(S_{11}\right)-E(G)\right] \\
G(q)=\frac{\mathrm{d} q}{\mathrm{~d} t}=q\left[E\left(S_{21}\right)-E(P)\right]
\end{array}\right.
$$

\section{Model Analysis}

In order to explore the process and result of trust evolution between government and private sector, the above models need to be solved and analysed.

4.1. Model Solving. Substituting equations (1)-(6) into equation (7), we get

$$
\left\{\begin{array}{l}
F(p)=\frac{\mathrm{d} p}{\mathrm{~d} t}=p(1-p)\left[q\left(C_{1}-V_{1}\right)+(1-q)\left(D_{1}-W_{1}\right)\right], \\
G(q)=\frac{\mathrm{d} q}{\mathrm{~d} t}=q(1-q)\left[p\left(C_{2}-D_{2}\right)+(1-p)\left(V_{2}-W_{2}\right)\right] .
\end{array}\right.
$$

According to the stability theory of the first-order differential equations, let $\left\{\begin{array}{l}F(p)=0, \\ G(q)=0\end{array}\right.$; thus, the solution to the equations is the strategic equilibrium point of the replicate dynamic equation. The strategic equilibrium point of the replicate dynamic equation $E(p, q)$ is $E_{1}=(0,0), E_{2}=(0,1)$, $E_{3}=(1,0), E_{4}=(1,1)$, and when $0<\left(W_{2}-V_{2} / C_{2}-D_{2}-\right.$ $\left.V_{2}+W_{2}\right)<1,0<\left(W_{1}-D_{1} / C_{1}-D_{1}-V_{1}+W_{1}\right)<1, \quad E_{5}=$ $\left(\left(W_{2}-V_{2} / C_{2}-D_{2}-V_{2}+W_{2}\right), \quad\left(W_{1}-D_{1} / C_{1}-D_{1}-V_{1}\right.\right.$ $\left.\left.+W_{1}\right)\right)$.

The strategic equilibrium point obtained by the replicate dynamic equation is not necessarily the evolutionary stable strategy of the evolutionary game. The local stability of the system at these equilibrium points can be analysed according to the local stability of the corresponding Jacobian matrix of the system. The local stability implies the ability of the system to fall back to its initial point when a minor disturbance occurs. For instance, when the trust between the government and private sector is in a local stable state if some individual quality problems cause a minor change in the trust of the government in the private sector, whether the system can converge to the original state is a question that needs to be discussed. The aim of introducing the Jacobian matrix is to analyse the local stability of the system at $E_{1}$ to $E_{5}$. If the determinant of the Jacobian matrix $\operatorname{det} J>0$ and the trace of Jacobian matrix $\operatorname{tr} J^{<} 0$, it can fall back to the initial state when the disturbance occurs. Partial derivatives of $p$ and $q$ are obtained for the two replicate dynamic equations; thus, the Jacobian matrix is $\left[\begin{array}{ll}\partial F / \partial p & \partial F / \partial q \\ \partial G / \partial p & \partial G / \partial q\end{array}\right]$. By taking the derivative of the replicate dynamic equations, the Jacobian matrix can be converted to 


$$
\left[\begin{array}{cc}
(1-2 p)\left[q\left(C_{1}-V_{1}\right)+(1-q)\left(D_{1}-W_{1}\right)\right] & p(1-p)\left(C_{1}-V_{1}-D_{1}+W_{1}\right) \\
q(1-q)\left(C_{2}-D_{2}-V_{2}+W_{2}\right) & (1-2 q)\left[p\left(C_{2}-D_{2}\right)+(1-p)\left(V_{2}-W_{2}\right)\right]
\end{array}\right] .
$$

The determinant of the matrix is

$$
\begin{aligned}
\operatorname{det} J= & (1-2 p)(1-2 q)\left[q\left(C_{1}-V_{1}\right)+(1-q)\left(D_{1}-W_{1}\right)\right]\left[p\left(C_{2}-D_{2}\right)+(1-p)\left(V_{2}-W_{2}\right)\right] \\
& -p q(1-p)(1-q)\left(C_{1}-V_{1}-D_{1}+W_{1}\right)\left(C_{2}-D_{2}-V_{2}+W_{2}\right) .
\end{aligned}
$$

The trace of the matrix is

$$
\begin{aligned}
\operatorname{tr} J= & (1-2 p)\left[q\left(C_{1}-V_{1}\right)+(1-q)\left(D_{1}-W_{1}\right)\right] \\
& +(1-2 q)\left[p\left(C_{2}-D_{2}\right)+(1-p)\left(V_{2}-W_{2}\right)\right] .
\end{aligned}
$$

If and only if the determinant of the matrix at the policy equilibrium point is greater than zero and the trace of the matrix is less than zero, this point is an evolutionarily stable strategy of the evolutionary game [49]. The five equilibrium

For equilibrium point $E_{1}=(0,0)$, according to stability criteria, there is

$$
\left\{\begin{array}{l}
\operatorname{det} J=\left(D_{1}-W_{1}\right)\left(V_{2}-W_{2}\right)>0 \\
\operatorname{tr} J=\left(D_{1}-W_{1}\right)+\left(V_{2}-W_{2}\right)<0 .
\end{array}\right.
$$

By solving the equations, we can derive $D_{1}<W_{1}$, $V_{2}<W_{2}$; that is, when $D_{1}<W_{1}, V_{2}<W_{2}$, the equilibrium point $E_{1}=(0,0)$ is the evolutionarily stable strategy of the evolutionary game. Similarly, where $C_{1}<V_{1}, V_{2}>W_{2}$, point points of the strategy are analysed.

$E_{2}=(0,1)$ or $D_{1}>W_{1}, C_{2}<D_{2}$, point $E_{3}=(1,0)$, or when $C_{1}>V_{1}, C_{2}>D_{2}$, point $E_{4}=(1,1)$; these comprise the evolutionary stability strategy of the evolutionary game. For point $E_{5}$, the trace of the matrix is equal to 0 , and therefore, the Jacobian matrix cannot be used to judge the local stability of this point, while differential analysis can be used. By applying the Taylor expansion of $F(p)$ and $G(q)$ in equation (8) at point $E_{5}$, the linear approximation equation of the replicate dynamic equation at point $E_{5}$ is obtained:

$$
\left\{\begin{array}{l}
F(p)=0 p+\frac{\left(W_{2}-V_{2}\right)\left(C_{2}-D_{2}\right)\left(C_{1}-V_{1}-D_{1}+W_{1}\right)}{\left(C_{2}-D_{2}-V_{2}+W_{2}\right)^{2}} q, \\
G(q)=\frac{\left(W_{1}-D_{1}\right)\left(C_{1}-V_{1}\right)\left(C_{2}-V_{2}-D_{2}+W_{2}\right)}{\left(C_{1}-D_{1}-V_{1}+W_{1}\right)^{2}} p+0 q .
\end{array}\right.
$$

The coefficient matrix of equation (13) is

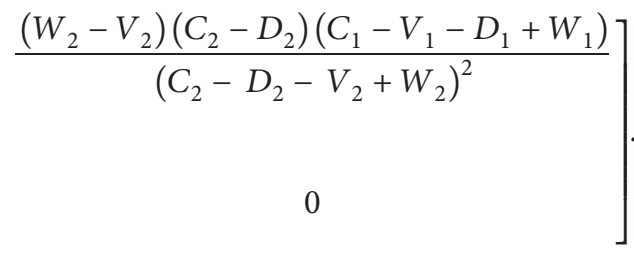

identity matrix, and the root of $f(\lambda)=0$ which is the characteristic root of $A$ : matrix the determinant of $\lambda E-A$ is the characteristic polynomial of $A$, denoted by $f(\lambda)=|\lambda E-A|$, where $E$ is the

\section{$\lambda$}

$\begin{gathered}-\frac{\left(W_{2}-V_{2}\right)\left(C_{2}-D_{2}\right)\left(C_{1}-V_{1}-D_{1}+W_{1}\right)}{\left(C_{2}-D_{2}-V_{2}+W_{2}\right)^{2}} \\ \lambda\end{gathered} \mid=0$.
By solving this determinantal equation, the characteristic roots of this linear differential equation are 
TABLe 2: The positive and negative conditions of the determinant and trace.

\begin{tabular}{lcc}
\hline Equilibrium point & $\operatorname{det} J$ & \\
\hline$E_{1}(0,0)$ & + & + \\
$E_{2}(0,1)$ & + & + \\
$E_{3}(1,0)$ & + & - \\
$E_{4}(1,1)$ & Uncertain \\
$E_{5}\left(\left(W_{2}-V_{2} / C_{2}-D_{2}-V_{2}+W_{2}\right),\left(W_{1}-D_{1} / C_{1}-D_{1}-V_{1}+W_{1}\right)\right)$ & + \\
\hline
\end{tabular}

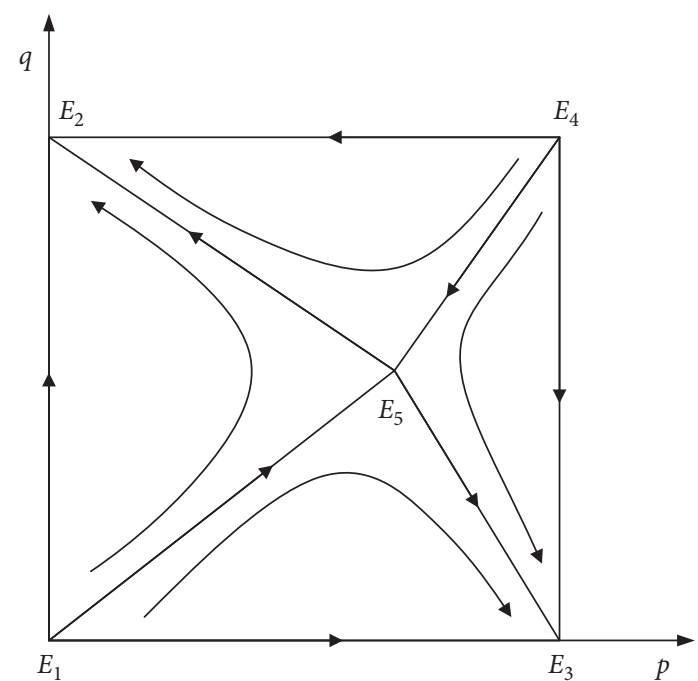

FIgURE 1: Replicate dynamic equation phase diagram when $D_{1}>W_{1}, V_{2}>W_{2}, C_{1}<V_{1}, C_{2}<D_{2}$.

$$
\lambda_{1,2}= \pm \sqrt{\frac{\left(W_{1}-D_{1}\right)\left(C_{1}-V_{1}\right)\left(W_{2}-V_{2}\right)\left(C_{2}-D_{2}\right)}{\left(C_{1}-D_{1}-V_{1}+W_{1}\right)\left(C_{2}-D_{2}-V_{2}+W_{2}\right)}}
$$

The characteristic root is a real root with a different sign, so the equilibrium point $E_{5}$ is an unstable saddle point.

4.2. Model Analysis. According to the solution above, the evolution process, stable state, and influencing factors of the model could be analysed. The analysis results show that the model has four possible evolutionary stable states, and the four stable states can be divided into two groups based on whether the strategies adopted by the players are symmetrical or not, when $D_{1}>W_{1}, V_{2}>W_{2}, C_{1}<V_{1}, C_{2}<D_{2}$, players tend to asymmetry strategies, but when $D_{1}<W_{1}$, $V_{2}<W_{2}, C_{1}>V_{1}, C_{2}>D_{2}$, players tend to symmetry strategies. The detailed analysis is as follows.

4.3. Asymmetry Strategies. When $D_{1}>W_{1}, V_{2}>W_{2}$, $C_{1}<V_{1}, C_{2}<D_{2}$, the positive and negative conditions of the determinant and trace of the Jacobian matrix at the five equilibrium points are shown in Table 2.

In this case, $E_{2}$ and $E_{3}$ are stable points, $E_{1}$ and $E_{4}$ are unstable points, and $E_{5}$ are saddle points. The replicate dynamic equation phase diagram is shown in Figure 1.

This indicates that when $D_{1}>W_{1} D, V_{2}>W_{2}, C_{1}<V_{1}$, $C_{2}<D_{2}$, point $E(p, q)$, which represents the initial willingness $p$ and $q$ of the government and private sector, respectively, to choose the trust strategy, is located in region $E_{1} E_{2} E_{4} E_{5}$, and the game will be stable at point $E_{2}(0,1)$, with the final strategic profile of players tending to distrust, trust; when the point $E(p, q)$ is located in region $E_{1} E_{3} E_{4} E_{5}$, the evolutionary game will be stable at the point $E_{3}(1,0)$, and the final strategic profile of players will tend to trust, distrust. Hence, when area $S_{1}$ of region $E_{1} E_{2} E_{4} E_{5}$ increases, the probability of the system's final evolution to the stable point $E_{2}(0,1)$ increases; conversely, when the area of this region decreases, the probability of the system's final evolution to the stable point $E_{3}(1,0)$ increases.

According to the coordinates of point $E_{5}\left(\left(W_{2}-V_{2} /\right.\right.$ $\left.\left.C_{2}-D_{2}-V_{2}+W_{2}\right),\left(W_{1}-D_{1} / C_{1}-D_{1}-V_{1}+W_{1}\right)\right)$, the area of $S_{1}$ is

$$
\begin{aligned}
S_{1} & =\frac{1}{2}\left(\frac{W_{2}-V_{2}}{C_{2}-D_{2}-V_{2}+W_{2}}+1-\frac{W_{1}-D_{1}}{C_{1}-D_{1}-V_{1}+W_{1}}\right) \\
& =\frac{1}{2}\left(\frac{1}{1+\left(C_{2}-D_{2} / W_{2}-V_{2}\right)}-\frac{1}{1+\left(C_{1}-V_{1} / W_{1}-D_{1}\right)}\right)+\frac{1}{2} .
\end{aligned}
$$

herefore, when $D_{1}>W_{1}, V_{2}>W_{2}, C_{1}<V_{1}, C_{2}<D_{2}$, area $S_{1}$ increases with the increase in $C_{1}, D_{1}, D_{2}, W_{2}$ and decreases with the increase in $C_{2}, V_{1}, V_{2}, W_{1}$. Thus, the probability that the evolutionary game stabilises to point $E_{2}(0,1)$ increases with the increase in $C_{1}, D_{1}, D_{2}, W_{2}$ and decreases with the increase in $C_{2}, V_{1}, V_{2}, W_{1}$.

4.4. Symmetry Strategies. When $D_{1}<W_{1}, V_{2}<W_{2}, C_{1}>V_{1}$, $C_{2}>D_{2}$, the positive and negative conditions of the determinant and trace of the Jacobian matrix at the five equilibrium points are shown in Table 3 .

In this case, $E_{1}$ and $E_{4}$ are stable points, $E_{2}$ and $E_{3}$ are unstable points, and $E_{5}$ are saddle points. The replicate dynamic equation phase diagram is shown in Figure 2.

This indicates that when $D_{1}<W_{1}, V_{2}<W_{2}, C_{1}>V_{1}$, $C_{2}>D_{2}$, point $E(p, q)$, which represents the initial willingness $p$ and $q$ of the government and private sector, respectively, to choose a trust strategy, is located in region $E_{1} E_{2} E_{5} E_{3}$, the game will be stable at point $E_{1}(0,0)$, and the final strategic profile of players tends to distrust, distrust; when point $E(p, q)$ is located in region $E_{4} E_{2} E_{5} E_{3}$, the evolutionary game will be stable at point $E_{4}(1,1)$, and the final strategic profile of players will tend to trust, trust. Hence, when the area $S_{2}$ of region $E_{1} E_{2} E_{5} E_{3}$ increases, the probability of the system's final evolution to the stable point $E_{1}(0,0)$ increases; conversely when the area of this region 
TABLE 3: The positive and negative conditions of the determinant and trace.

\begin{tabular}{lcc}
\hline Equilibrium point & $\operatorname{det} J$ & \\
\hline$E_{1}(0,0)$ & + & + \\
$E_{2}(0,1)$ & + & + \\
$E_{3}(1,0)$ & + & + \\
$E_{4}(1,1)$ & Uncertain & + \\
$E_{5}\left(\left(W_{2}-V_{2} / C_{2}-D_{2}-V_{2}+W_{2}\right),\left(W_{1}-D_{1} / C_{1}-D_{1}-V_{1}+W_{1}\right)\right)$ & - \\
\hline
\end{tabular}

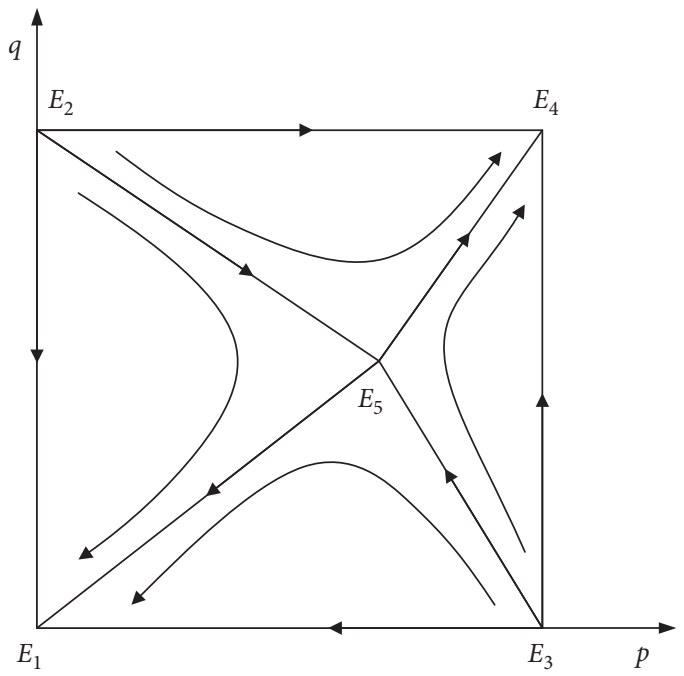

FIgURE 2: Replicate dynamic equation phase diagram when $D_{1}<W_{1}, V_{2}<W_{2}, C_{1}>V_{1}, C_{2}>D_{2}$.

TABle 4: Parameter settings for the numerical experiment.

\begin{tabular}{lcccc}
\hline \multirow{2}{*}{ Parameters } & \multicolumn{4}{c}{ Series number } \\
& 1 & 2 & 3 & 4 \\
\hline$p$ & 0.3 & 0.5 & 0.5 & 0.6 \\
$q$ & 0.6 & 0.4 & 0.5 & 0.5 \\
$D_{1}$ & 8 & 8 & 4 & 4 \\
$W_{1}$ & 5 & 5 & 7 & 7 \\
$V_{2}$ & 6 & 6 & 2 & 2 \\
$W_{2}$ & 4 & 4 & 5 & 5 \\
$C_{1}$ & 3 & 3 & 4 & 4 \\
$V_{1}$ & 5 & 5 & 2 & 2 \\
$C_{2}$ & 4 & 4 & 6 & 6 \\
$D_{2}$ & 7 & 7 & 3 & 3 \\
\hline
\end{tabular}

decreases, the probability of the system's final evolution to the stable point $E_{4}(1,1)$ increases.

According to the coordinates of point $E_{5}\left(\left(W_{2}-V_{2} /\right.\right.$ $\left.\left.C_{2}-D_{2}-V_{2}+W_{2}\right),\left(W_{1}-D_{1} / C_{1}-D_{1}-V_{1}+W_{1}\right)\right)$, the area of $S_{2}$ is

$$
\begin{aligned}
S_{2} & =\frac{1}{2}\left(\frac{W_{2}-V_{2}}{C_{2}-D_{2}-V_{2}+W_{2}}+\frac{W_{1}-D_{1}}{C_{1}-D_{1}-V_{1}+W_{1}}\right) \\
& =\frac{1}{2}\left(\frac{1}{1+\left(C_{2}-D_{2} / W_{2}-V_{2}\right)}+\frac{1}{1+\left(C_{1}-V_{1} / W_{1}-D_{1}\right)}\right) .
\end{aligned}
$$

Therefore, when $D_{1}<W_{1}, V_{2}<W_{2}, C_{1}>V_{1}, C_{2}>D_{2}$, ceteris paribus, area $S_{2}$ decreases with the increase in $C_{1}, C_{2}$,

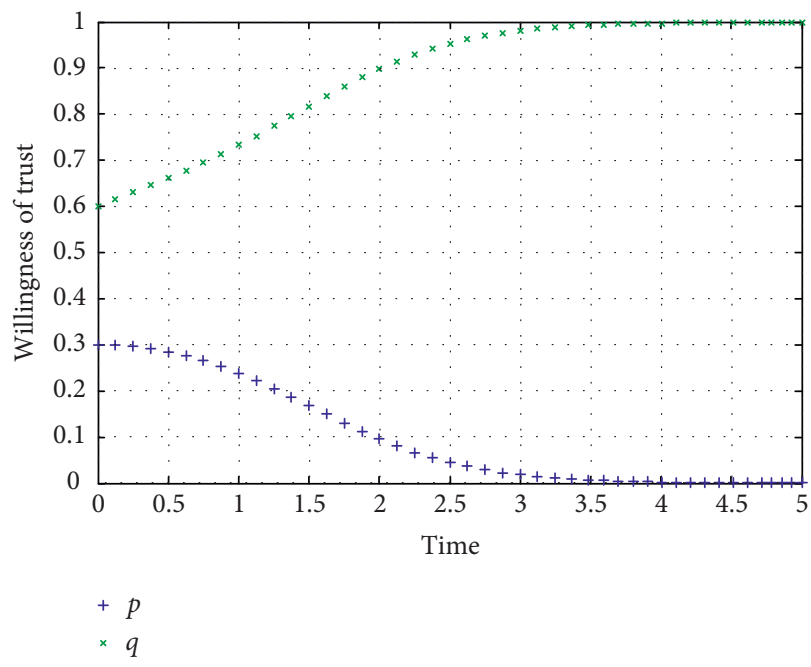

Figure 3: Result of simulation 1.

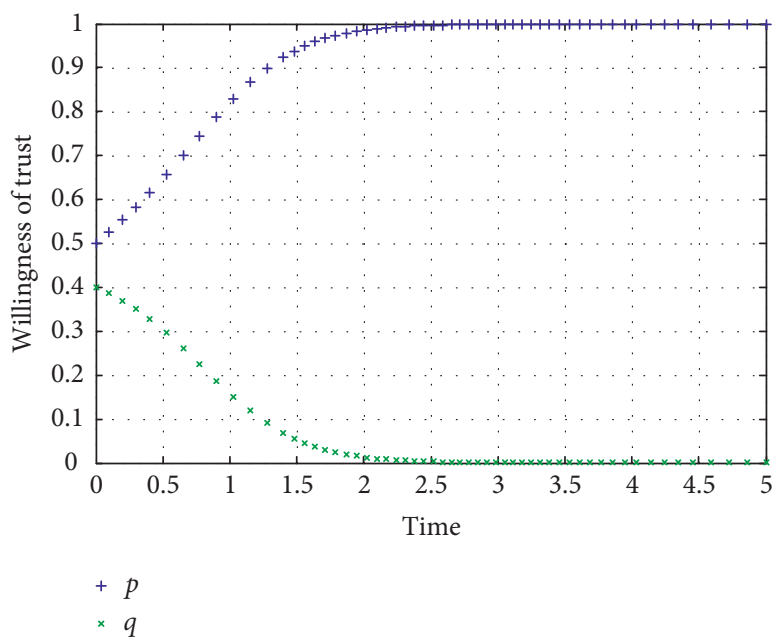

Figure 4: Result of simulation 2.

$D_{1}, V_{2}$ and increases with the increase in $W_{1}, W_{2}, D_{2}, V_{1}$. Thus, the probability that the evolutionary game stabilises to point $E_{2}(0,1)$ decreases with the increase in $C_{1}, C_{2}, D_{1}, V_{2}$ and increases with the increase in $W_{1}, W_{2}, D_{2}, V_{1}$.

\section{Numerical Experiment}

Based on the evolutionary game model proposed, MATLAB R2012a was applied to perform a numerical experiment. Further analysis and demonstration are made on the relevant conclusions drawn by the evolutionary game model. 


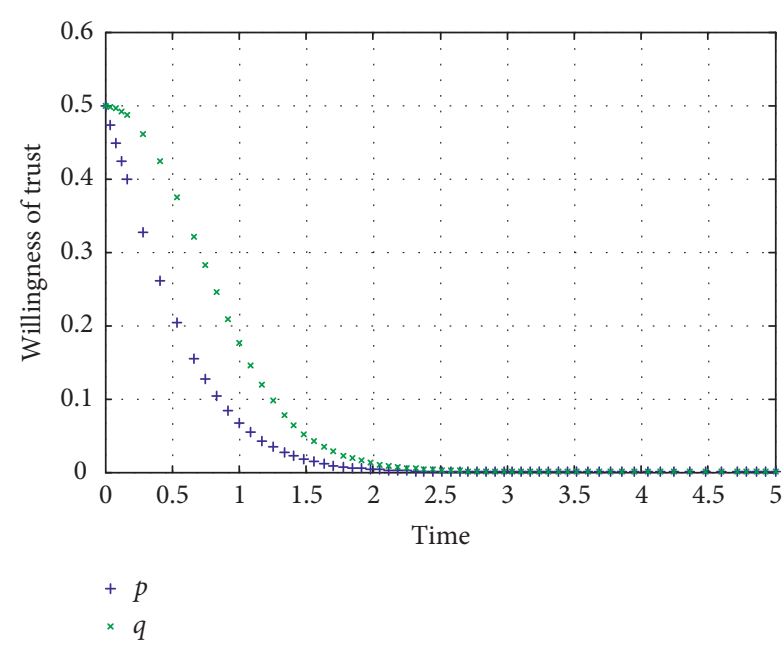

Figure 5: Result of simulation 3.

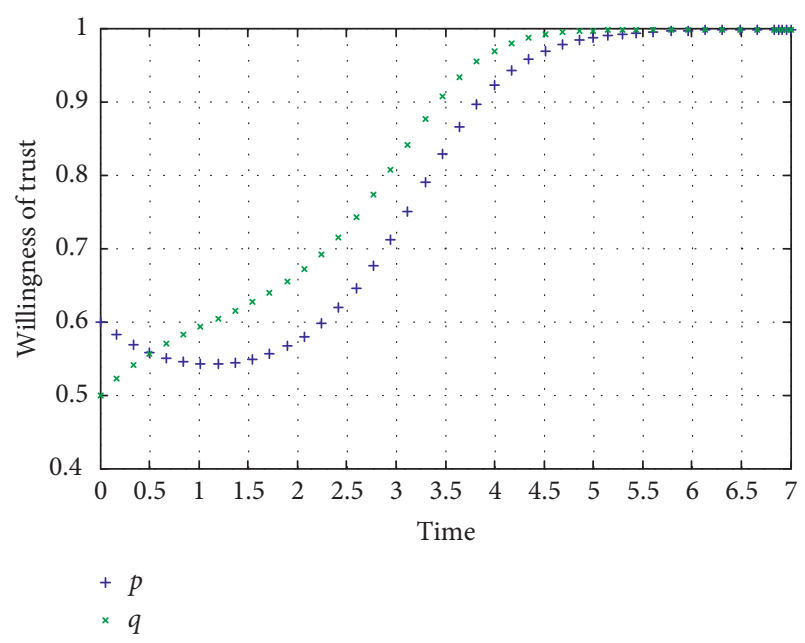

Figure 6: Result of simulation 4.

The parameter settings of the numerical experiment are presented in Table 4.

The first and second data columns were used to verify the process and result of asymmetry strategies. The numerical simulation results appear in Figures 3 and 4. Under the condition of $D_{1}>W_{1}, V_{2}>W_{2}, C_{1}<V_{1}, C_{2}<D_{2}$, when the initial values of $p$ and $q$ are 0.3 and 0.6 , respectively, the game was stable at point $E_{2}(0,1)$, and when the initial values of $p$ and $q$ are 0.5 and 0.4 , respectively, the game was stable at point $E_{3}(1,0)$.

The third and fourth data columns are used to verify the process and result of symmetry strategies. The numerical simulation results appear in Figures 5 and 6. Under the condition of $D_{1}<W_{1}, V_{2}<W_{2}, C_{1}>V_{1}, C_{2}>D_{2}$, when the initial values of $p$ and $q$ are 0.5 and 0.5 , respectively, the game was stable at point $E_{1}(0,0)$, and when the initial values of $p$ and $q$ are 0.6 and 0.5 , respectively, the game was stable at point $E_{4}(1,1)$.

\section{Discussion}

The model analysis and numerical experiment show that the trust evolution process and evolutionary stable state between government and private sector are related to the initial trust and payment matrix of the game. When $D_{1}>W_{1}, V_{2}>W_{2}, C_{1}<V_{1}, C_{2}<D_{2}$, the final evolutionary stable state of the system entails one player adopting the trust strategy while the other adopts the distrust strategy. The probability that the evolutionary game stabilises to where the government adopts a distrust strategy and the private sector adopts a trust strategy increases with the increase in $C_{1}, D_{1}, D_{2}, W_{2}$ and decreases with the increase in $C_{2}, V_{1}, V_{2}, W_{1}$. Conversely, the probability that the evolutionary game stabilises to where government adopts a trust strategy and private sector adopts a distrust strategy decreases with an increase in $C_{1}, D_{1}, D_{2}, W_{2}$ and increases with the increase in $C_{2}, V_{1}, V_{2}, W_{1}$. When $D_{1}<W_{1}$, $V_{2}<W_{2}, C_{1}>V_{1}, C_{2}>D_{2}$, the probability that the evolutionary game stabilises to a position of mutual distrust decreases with the increase in $C_{1}, C_{2}, D_{1}, V_{2}$ and increases with the increase in $W_{1}, W_{2}, D_{2}, V_{1}$. Conversely, the probability that the evolutionary game stabilises to a position of mutual trust increases with the increase in $C_{1}, C_{2}$, $D_{1}, V_{2}$ and decreases with the increase in $W_{1}, W_{2}, D_{2}, V_{1}$.

When both the government and private sectors adopt the distrust strategy, the costs of information, bargaining, decision-making, and constraints of both parties will increase [50-52]. From the perspective of PPP project management, this situation should, wherever possible, be avoided.

In PPP projects, if either the government or private sector adopts a trust strategy while the other party adopts a distrust strategy, the transaction cost will be somewhat increased. Moreover, if the government adopts a trust strategy while the private sector adopts a distrust strategy, the enthusiasm of the private sector to participate in the construction of public infrastructure and public services may be negatively affected. In the process of cooperation, the private sector is likely to consider its own benefits (to reduce the probability of losses caused by the government's breach of trust) ahead of the overall objectives of the project. Alternatively, if the government adopts a strategy of distrust while the private sector adopts a strategy of trust, this may negatively influence the initiatives of the government to include the private sector in the production of public goods, which is not conducive to the efficient development of the economy. The government may strengthen its supervision and control over the private sector, thus prohibiting it from fully exercising its advantages and thereby negatively affecting the efficiency of the project.

When both the government and the private sector adopt trust strategies, the performance of PPP projects can be improved due to reduced transaction costs $[53,54]$. Mutual trust reduces high contract execution costs and opportunistic behaviours caused by contract incompletion and future uncertainty and is thus crucial for improving cooperation efficiency. Higher levels of trust between the government and the private sector result in enhanced satisfaction for both parties in this cooperative relationship. When the satisfaction levels of both parties are high, they tend to take the initiative to implement mutually beneficial projects to improve the efficiency of their cooperation, thus further improving project performance. 


\section{Conclusion and Limitations}

To reveal the processes of evolution and mechanisms of trust between the government and private sector in PPP project networks, this study constructs an evolutionary game model to analyse this problem while using the Jacobian matrix and the differential equation stability theory to explore the stable state. The results show that the four stable strategy profiles$\{$ trust, distrust $\},\{$ distrust, trust $\},\{$ trust, trust $\}$, and $\{$ distrust, distrust $\}$ - and the initial payoff matrix of the game have a predictive effect on the evolution process and stable strategy.

This study analyses and discusses the evolution of trust between the government and private sector in PPP projects by using the evolutionary game model, which provides an alternative approach to solving the complex trust problems in PPP project networks. In practice, the trust state between the government and private sector has an important impact on project performance, while the evolution process and the stable state of trust between both parties are affected by their mutual expected payoffs. The method proposed in this study can thus be used to predict the evolution of trust between the government and private sector, while the simultaneous and reasonable design of the payoffs can effectively control the trust evolution process and trust stable state of both parties to improve project performance.

There are, however, numerous issues that require further future study. To simplify the analysis process, the payoffs of government and private sector under different strategy profiles are represented in a highly simplified manner; thus, a more complex payoff matrix should be constructed based on more realistic scenarios facing PPP projects, thereby further exploring the detailed factors influencing the evolution of interorganisational trust. Some previous studies have provided some methods for reference. For instance, Yuan et al. proposed a conceptual KPIs framework that includes five indicators from the perspective of government, such as physical characteristics, financing and marketing, innovation and learning, stakeholders, and process [55]. Glumac et al. tried the method of game theoretical experiment [56]. Carbonara and Pellegrino proposed a model to evaluate the benefits of all parties based on NPV (net present value) [57]. Additionally, although the government and private sector are two important participants in PPP projects, there are other stakeholders including, banks, citizens, and insurance companies. These stakeholders, together with the government and private sector, are mutually interlinked and informed within a complex trust network that needs to be further explored in future research on PPP projects.

\section{Data Availability}

The data and code used to support the findings of this study are available from the corresponding author upon request.

\section{Conflicts of Interest}

The authors declare that there are no conflicts of interest regarding the publication of this paper.

\section{Authors' Contributions}

Xiangtian Nie contributed to the conception of the study; Kai Feng contributed to the methodology and wrote the original draft; Kai Feng and Tianyu Fan performed the numerical experiment; Shengnan Wang reviewed and edited the article; Guoxiang Zhao contributed significantly to project administration. All the authors have read and agreed to the published version of the manuscript.

\section{Acknowledgments}

This research was supported by the Doctoral Innovation Fund of North China University of Water Resources and Electric Power.

\section{References}

[1] Q. Shi, J. Zhu, and Q. Li, "Cooperative evolutionary game and applications in construction supplier tendency," Complexity, vol. 2018, Article ID 8401813, 13 pages, 2018.

[2] X. Zheng, Y. Le, A. P. C. Chan, Y. Hu, and Y. Li, "Review of the application of social network analysis (SNA) in construction project management research," International Journal of Project Management, vol. 34, no. 7, pp. 1214-1225, 2016.

[3] G. Wu, X. Zhao, J. Zuo, and G. Zillante, "Effects of team diversity on project performance in construction projects," Engineering, Construction and Architectural Management, vol. 26, no. 3, pp. 408-423, 2019.

[4] G. Wu, Z. Hu, J. Zheng, X. Zhao, and J. Zuo, "Effects of structure characteristics of project network on conflicts and project success," Engineering, Construction and Architectural Management, vol. 28, no. 1, 2019.

[5] Y. Du and Y. Wang, "Research on the dynamic evolvement of trust in PPP projects," Construction Economy, vol. 8, pp. 30-35, 2012.

[6] H. Wang, W. Xiong, G. Wu, and D. Zhu, "Public-private partnership in public administration discipline: a literature review," Public Management Review, vol. 20, no. 2, pp. 293-316, 2018.

[7] N. Carbonara and R. Pellegrino, "Revenue guarantee in public-private partnerships: a win-win model," Construction Management and Economics, vol. 36, no. 10, pp. 584-598, 2018.

[8] A. Lomoro, G. Mossa, R. Pellegrino, and L. Ranieri, "Optimizing risk allocation in public-private partnership projects by project finance contracts. the case of put-or-pay contract for stranded posidonia disposal in the municipality of bari," Sustainability, vol. 12, no. 3, p. 806, 2020.

[9] R. H. Coase, The Nature of the Firm, Oxford University Press, Oxford, UK, 1991.

[10] R. C. Mayer, J. H. Davis, and F. D. Schoorman, "An integrative model of organizational trust," Academy of Management Review, vol. 20, no. 3, pp. 709-734, 1995.

[11] A. Laan, H. Voordijk, N. Noorderhaven, and G. Dewulf, "Levels of interorganizational trust in construction projects: empirical evidence," Journal of Construction Engineering and Management, vol. 138, no. 7, pp. 821-831, 2011.

[12] B. L. Connelly, T. R. Crook, J. G. Combs, D. J. Ketchen, and H. Aguinis, "Competence- and integrity-based trust in interorganizational relationships: which matters more?" Journal of Management, vol. 44, no. 3, pp. 919-945, 2018. 
[13] P. S. Adler, "Market, hierarchy, and trust: the knowledge economy and the future of capitalism," Organization Science, vol. 12, no. 2, pp. 215-234, 2001.

[14] M. D. Ryall and R. C. Sampson, "Formal contracts in the presence of relational enforcement mechanisms: evidence from technology development projects," Management Science, vol. 55, no. 6, pp. 906-925, 2009.

[15] H. J. Lee, "The role of competence-based trust and organizational identification in continuous improvement," Journal of Managerial Psychology, vol. 19, no. 6, pp. 623-639, 2004.

[16] J. M. Whipple and R. Frankel, "Strategic alliance success factors," The Journal of Supply Chain Management, vol. 36, no. 3, pp. 21-28, 2000.

[17] J. J. Li, L. Poppo, and K. Z. Zhou, "Relational mechanisms, formal contracts, and local knowledge acquisition by international subsidiaries," Strategic Management Journal, vol. 31, pp. 349-370, 2010.

[18] A. Zaheer, B. McEvily, and V. Perrone, "Does trust matter? exploring the effects of interorganizational and interpersonal trust on performance," Organization Science, vol. 9, no. 2, pp. 141-159, 1998.

[19] R. Gulati, "Alliances and networks," Strategic Management Journal, vol. 19, no. 4, pp. 293-317, 1998.

[20] A. Larson, "Network dyads in entrepreneurial settings: a study of the governance of exchange relationships," Administrative Science Quarterly, vol. 37, no. 1, pp. 76-104, 1992.

[21] D. Wu, Y. Jian, and Y. Yu, "Research on the influencing factors of inter-organizational trust in PPP projects," Journal of Wuhan University of Technology (Information \& Management Engineering), vol. 38, no. 6, pp. 750-754, 2016.

[22] A. Brinkhoff, Ö. Özer, and G. Sargut, "All you need is trust? an examination of inter-organizational supply chain projects," Production and Operations Management, vol. 24, no. 2, pp. 181-200, 2015.

[23] P. A. Pavlou, "Institution-based trust in interorganizational exchange relationships, the role of online B2B marketplaces on trust formation," Journal of Strategic Information System, vol. 11, no. 3-4, pp. 215-234, 2002.

[24] S. S. Lui, H.-Y. Ngo, and A. H. Y. Hon, "Coercive strategy in interfirm cooperation: mediating roles of interpersonal and interorganizational trust," Journal of Business Research, vol. 59, no. 4, pp. 466-474, 2006.

[25] S. B. Zhang, J. Chen, and Y. Fu, "Contract complexity and trust in construction project subcontracting," Engineering, Construction and Architecture Management, vol. 27, no. 9, 2020.

[26] X. Shi and Z. Liao, "Inter-firm dependence, inter-firm trust, and operational performance: the mediating effect of e-business integration," Information \& Management, vol. 52, no. 8, pp. 943-950, 2015.

[27] D. A. Johnston, D. M. McCutcheon, F. I. Stuart, and H. Kerwood, "Effects of supplier trust on performance of cooperative supplier relationships," Journal of Operations Management, vol. 22, no. 1, pp. 23-38, 2004.

[28] M. Sinaceur, "Suspending judgments to create value, suspicion, distrust, and trust in negotiations," Unpublished Doctoral Dissertation, Stanford University, Stanford, CA, USA, 2005.

[29] G. Szulanski, R. Cappetta, and R. J. Jensen, "When and how trustworthiness matters: knowledge transfer and the moderating effect of causal ambiguity," Organization Science, vol. 15, no. 5, pp. 600-613, 2004.
[30] M. E. Graebner, F. Lumineau, and D. Fudge Kamal, "Unrequited: asymmetry in interorganizational trust," Strategic Organization, vol. 18, no. 2, pp. 362-374, 2020.

[31] Y. Li, N. He, H. Li, Z. Liu, and J. Qi, "Influencing factors on inter-organizational trust asymmetry behavior in construction projects," Engineering, Construction and Architectural Management, vol. 28, no. 1, pp. 308-331, 2019.

[32] F. D. Schoorman, R. C. Mayer, and J. H. Davis, "An integrative model of organizational trust: past, present, and future," Academy of Management Review, vol. 32, no. 2, pp. 344-354, 2007.

[33] T. V. Nguyen, "Learning to trust: a study of interfirm trust dynamics in Vietnam," Journal of World Business, vol. 40, no. 2, pp. 203-221, 2005.

[34] A. Laan, Building Trust, The Case of the Construction Industry, University of Twente, Enschede, Netherlands, 2008.

[35] Z. Fu and H. Gu, "Optimal trust, a study on dynamic evolution of interfirm relations in SME clusters," Review of Industrial Economics, vol. 10, no. 1, pp. 1-22, 2011.

[36] D. Xiao and X. Gu, "Research on inter-organizational trust formation mechanism in knowledge networks-based on the perspective of game theory," Science and Technology Management Research, vol. 3, pp. 212-214, 2009.

[37] L. Yuan and X. Zhang, "Constructing route to trust relationship of organizations with touching off tactics," Systems Engineering, vol. 4, pp. 15-18, 2005.

[38] G. Zhu, H. Liu, and M. Feng, "Sustainability of information security investment in online social networks: an evolutionary game-theoretic approach," Mathematics, vol. 6, no. 10, p. 177, 2018.

[39] J. Luo, "The default punishment mechanism of cooperation among enterprises based on evolutionary game theory," Systems Engineering, vol. 1, pp. 27-31, 2012.

[40] C.-F. Li, L.-Y. Zhang, G.-C. Zhao, and L.-J. Mo, "Research on basin ecological compensation based on evolutionary game theory-taking Taihu Basin as a case," China Population, Resources and Environment, vol. 24, no. 1, pp. 171-176, 2014.

[41] M. Zhang, J. Zhu, H. Wang, and P. Liu, "Evolutionary game analysis on strategies in "main manufacturer-supplier" mode considering technology docking and price concluding under competition condition," Mathematics, vol. 7, no. 12, p. 1184, 2019.

[42] M. Zhang, J. Zhu, P. Kumaraswamy, and H. Wang, "Evolutionary game analysis of the effects of problem size and the problem proposing mechanism on the problem processing mechanism in a new main manufacturersupplier collaborative system," Mathematics, vol. 7, no. 7, p. $588,2019$.

[43] A. Abdullah and I. Khadaroo, "The trust-control nexus in public private partnership (PPP) contracts," Journal of Accounting and Public Policy, vol. 39, no. 6, 2020.

[44] L. English and J. Baxter, "The changing nature of contracting and trust in public-private partnerships: the case of victorian PPP prisons," Abacus, vol. 46, no. 3, pp. 289-319, 2010.

[45] G. Dewulf and M. J. Garvin, "Responsive governance in PPP projects to manage uncertainty," Construction Management and Economics, vol. 38, no. 4, pp. 383-397, 2020.

[46] Y. Huang and I. F. Wilkinson, "The dynamics and evolution of trust in business relationships," Industrial Marketing Management, vol. 42, no. 3, pp. 455-465, 2020.

[47] A. Kumar, V. Capraro, and M. Perc, "The evolution of trust and trustworthiness," Journal of the Royal Society, Interface, vol. 17, no. 169, Article ID 20200491, 2020.

[48] D. Friedman, "Evolutionary games in economics," Econometrica, vol. 59, no. 3, pp. 637-666, 1991. 
[49] D. Friedman, "On economic applications of evolutionary game theory," Journal of Evolutionary Economics, vol. 8, no. 1, pp. 15-43, 1998.

[50] I. H. Chow, "How trust reduces transaction costs and enhances performance in China's businesses," SAM Advanced Management Journal, vol. 73, no. 2, p. 25, 2008.

[51] J. H. Dyer and W. Chu, "The role of trustworthiness in reducing transaction costs and improving performance: empirical evidence from the United States, Japan, and Korea," Organization Science, vol. 14, no. 1, pp. 57-68, 2003.

[52] R. Cai and W. Ma, "Trust, transaction costs, and contract enforcement: evidence from apple farmers in China," British Food Journal, vol. 117, no. 10, pp. 2598-2608, 2015.

[53] M. Beccerra and A. K. Gupta, "Trust within the organization, integrating the trust literature with agency theory and transaction costs economics," Public Administration Quarterly, vol. 23, no. 2, pp. 177-203, 1999.

[54] G. Hendrikse, P. Hippmann, and J. Windsperger, "Trust, transaction costs and contractual incompleteness in franchising," Small Business Economics, vol. 44, no. 4, pp. 867-888, 2015.

[55] J. Yuan, A. Y. Zeng, M. J. Skibniewski, and Q. Li, "Selection of performance objectives and key performance indicators in public-private partnership projects to achieve value for money," Construction Management and Economics, vol. 27, no. 3, pp. 253-270, 2009.

[56] B. Glumac, Q. Han, W. Schaefer, and E. van der Krabben, "Negotiation issues in forming public-private partnerships for brownfield redevelopment: applying a game theoretical experiment," Land Use Policy, vol. 47, pp. 66-77, 2015.

[57] N. Carbonara and R. Pellegrino, "Public-private partnerships for energy efficiency projects: a win-win model to choose the energy performance contracting structure," Journal of Cleaner Production, vol. 170, pp. 1064-1075, 2018. 